Trinity University

Digital Commons@ Trinity

Art and Art History Faculty Research

Art and Art History Department

2013

\title{
Pre-objective Depth in Merleau-Ponty and Jackson Pollock
}

Michael Schreyach

TrinityUniversity, mschreya@trinity.edu

Follow this and additional works at: http://digitalcommons.trinity.edu/art_faculty

Part of the History of Art, Architecture, and Archaeology Commons

\section{Repository Citation}

Schreyach, M. (2013). Pre-Objective Depth in Merleau-Ponty and Jackson Pollock. Research in Phenomenology, 43(1), 49-70.

This Article is brought to you for free and open access by the Art and Art History Department at Digital Commons @ Trinity. It has been accepted for inclusion in Art and Art History Faculty Research by an authorized administrator of Digital Commons @ Trinity. For more information, please contact jcostanz@trinity.edu. 


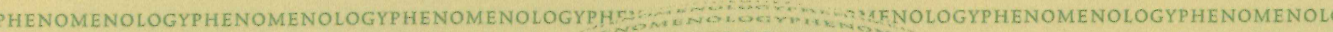
PHENOMENOLOGYPHENOMENOLOGYPHENOMENOW WENOMENOLOCYTW NOM Y SYPHENOMENOLOGYPHENOMENOLC PHENOMENOLOGYPHENOMENOLOGYPHENOYG YPHENOMENOLOGYPHENOMEOL PHENOMENOLOGYPHENOMENOLOGYPHEN NOLOGYPHENOMENONOLOGYPHENOMENOLYYMENOLOGYPHENOMENOLO PHENOMENOLOGYPHENOMENOLOGYP NOLOGYPHENOMENOLOGY NOLOGYPHENOMENOLYYHY NOLOGYPHENOMENOLC PHENOMENOLOGYPHENOMENOLOG N NOLOLOGPHENOMENOLOGYPHENOMENOLOGYPHE WLOGYPHENOMENOLC PHENOMENOLOGYPHENOMENOLC NOMEN NOLOGYPHENOMENOLOGYPHENOMENOLOGYPHEMY SYYPHENOMENOLO PHENOMENOLOGYPHENOMENO RILNOMENOLOGYGPHENOMENOLOGYPHENOMENOLOGYPHENOY YPHENOMENOLC PHENOMENOLOGYPHENOMEN HENOMENOLOGYPHENOMENOLOGYPHENOMENOLOGYPHENOME "PHENOMENOLC PHENOMENOLOGYPHENOME HENOMENOLOGYPHENOMENOLOGYPHENOMENOLOGYPHENOMEKE HENOMENOLO PHENOMENOLOGYPHENOMY PHENOMENOLOGYPHENOMENOLOGYPHENOMENOLOGYPHENOMENOENOMENOLC PHENOMENOLOGYPHENOM PHENOMENOLOGYPHENON PHENOMENOLOGYPHENONEGYHENOMENOLOGYPHENOMENOLOGYPHENOMENOLOGYPHENOMENOUEENOMENOLC PHENOMENOLOGYPHENON MGYPHENOMENOLOGYPHENOMENOLOGYPHENOMENOLOGYPHENOMENOTOENOMENOLO PHENOMENOLOGYPHENOM PHENOMENOLOGYPHENOML NOLOGYPHENOMENOLOG TO NOLOGYP HENOMENOLOGYPHENOMENOLOGY H L LOGYPHENOMENOLO 'HENOMENOLOGYPHENOMENOLOGY W YOGYPHENOMENOLOGYPHENOMENOLOGY " NOLOGYPHENOMENOLO PHENOMENOLOGYPHENOMENOLOGYPHEXYOLOGYPHENOMENOLOGYPHENOMEN OLO W WMNOLOGYPHENOMENOLO PHENOMENOLOGYPHENOMENOLOGYPHENOK WGYYENOMENOLOGYPHENOMENOL OU ZNOMENOLOGYPHENOMENOLO PHENOMENOLOGYPHENOMENOLOGYPHENOMENU.YWW NOMENOLOGYPHENOMNN SIYPHENOMENOLOGYPHENOMENOLO

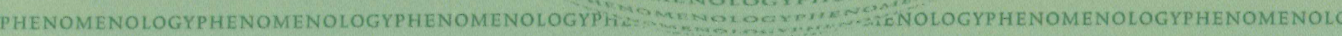
PHENOMENOLOGYPHENOMENOLOGYPHENOMENOLOGYPHENOMENOLOGYPHENOMENOLOGYPHENOMENOLOGYPHENOMENOLO PHENOMENOLOGYPHENOMENOLOGYPHENOMENOLOGYPHENOMENOLOGYPHENOMENOLOGYPHENOMENOLOGYPHENOMENOLO PHENOMENOLOGYPHENOMENOLOGYPHENOMENOLOGYPHENOMENOLOGYPHENOMENOLOGYPHENOMENOLOGYPHENOMENOLO PHENOMENOLOGYPHENOMENOLOGYPHENOMENOLOGYPHENOMENOLOGYPHENOMENOLOGYPHENOMENOLOGYPHENOMENOLO PHENOMENOLOGYPHENOMENOLOGYPHENOMENOLOGYPHENOMENOLOGYPHENOMENOLOGYPHENOMENOLOGYPHENOMENOLO PHENOMENOLOGYPHENOMENOLOGYPHENOMENOLOGYPHENOMENOLOGYPHENOMENOLOGYPHENOMENOLOGYPHENOMENOLO PHENOMENOLOGYPHENOMENOLOGYPHENOMENOLOGYPHENOMENOLOGYPHENOMENOLOGYPHENOMENOLOGYPHENOMENOLO PHENOMENOLOGYPHENOMENOLOGYPHENOMENOLOGYPHENOMENOLOGYPHENOMENOLOGYPHENOMENOLOGYPHENOMENOLO PHENOMENOLOGYPHENOMENOLOGYPHENOMENOLOGYPHENOMENOLOGYPHENOMENOLOGYPHENOMENOLOGYPHENOMENOLO PHENOMENOLOGYPHENOMENOLOGYPHENOMENOLOGYPHENOMENOLOGYPHENOMENOLOGYPHENOMENOLOGYPHENOMENOLO PHENOMENOLOGYPHENOMENOLOGYPHENOMENOLOGYPHENOMENOLOGYPHENOMENOLOGYPHENOMENOLOGYPHENOMENOLO PHENOMENOLOGYP HENOMENOLOGYPHENOMENOLOGYPHENOMENOLOGYPHENOMENOLOGYPHENOMENOLOGYPHENOMENOLO PHENOMENOLOGYPHENOMENOLOGYPHENOMENOLOGYPHENOMENOLOGYPHENOMENOLOGYPHENOMENOLOGYPHENOMENOLO PHENOMENOLOGYPHENOMENOLOGYPHENOMENOLOGYPHENOMENOLOGYPHENOMENOLOGYPHENOMENOLOGYPHENOMENOLO PHENOMENOLOGYPHENOMENOLOGYPHENOMENOLOGYPHENOMENOLOGYPHENOMENOLOGYPHENOMENOLOGYPHENOMENOLO PHENOMENOLOGYPHENOMENOLOGYPHENOMENOLOGYPHENOMENOLOGYPHENOMENOLOGYPHENOMENOLOGYPHENOMENOLO PHENOMENOLOGYPHENOMENOLOGYPHENOMENOYCGYPHENOMENOLOGYPHENOMENOLOGYPHENOMENOLOGYPHENOMENOLO PHENOMENOLOGYPHENOMENOLOGYPHENOMERULCHTENOMENOLOGYPHENOMENOLOGYPHENOMENOLOGYPHENOMENOLO 


\section{RESEARCH IN}

\section{Phenomenology}

\section{ARTICLES}

Darian Meacham

Niall Keane

Michael Schreyach

Rodolphe Gasché

What Goes Without Saying: Husserl's Concept of Style

The Silence of the Origin: Philosophy in Transition and the Essence of Thinking

Pre-objective Depth in Merleau-Ponty and

Jackson Pollock

\section{DISCUSSION}

Miracle and Machine: Jacques Derrida and the Two Sources of Religion, Science, and the Media by Michael Naas

In Love of Life: Michael Naas' Miracle and Machine

Fordham Roundtable Discussion:

Sarah Hammerschlag On Monstrous Shoulders: Literature, Fraud, and Faith in Derrida

Martin Hägglund

Beyond the Performative and the Constative

Penelope Deutscher

Auto-immunity, Sexual Violence, and Reproduction

Michael Naas

The Promise of Other Voices

\section{REVIEW ARTICLES}

Peg Birmingham

Natal Finitude: Syncopated Temporality and the Endurance of the New. Review of Natality and

Finitude by Anne O'Byrne

Jeffrey Powell

Language, Writing and Truth. Review of The Truth

(and Untruth) of Language: Heidegger, Ricoeur, and Derrida on Disclosure and Displacement by Gert-Jan van der Heiden 


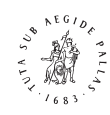

\title{
Pre-objective Depth in Merleau-Ponty and Jackson Pollock
}

\author{
Michael Schreyach \\ Trinity University
}

\begin{abstract}
Pollock's drip technique generated certain unconventional representational possibilities, including the possibility of expressing the pre-reflective involvement of an embodied, intentional subject in a perceptual world. Consequently, Pollock's art can be understood to explore or investigate the pre-objective conditions of reflective and intellectual consciousness. His painting-here I consider Number 1, 1949-motivates viewers to consider the relationship between intention and meaning as it appears in both primordial and reflective dimensions of experience. The account proceeds in three stages. First, I review key features of Merleau-Ponty's concept of the preobjective and attempt to clarify the reflexive nature of investigating it by considering his analysis of Paul Cézanne's technique. Second, I consider Pollock's technique and some critical responses to it, while analyzing some of its implications for a notion of pictorial address. Finally, I examine the perceptual effects of Number 1, 1949 and interpret them, following Merleau-Ponty's lead, in view of a revised understanding of the relationship between automatism and intention.
\end{abstract}

\section{Keywords}

interpretation, phenomenology, Maurice Merleau-Ponty, Jackson Pollock, automatism, intention

[W] have to rediscover beneath [objectified] depth ... a primordial depth, which confers upon it its significance, and which is the thickness of a medium devoid of any thing. ${ }^{1}$

[D]escription is not the return to immediate experience; one never returns to immediate experience. It is only a question of whether we are to try to understand it. ${ }^{2}$

1) Maurice Merleau-Ponty, The Phenomenology of Perception, trans. Colin Smith (London: Routledge, 1962), 266; hereafter cited as $P P$, followed by page number in the text.

2) Merleau-Ponty, "The Primacy of Perception and Its Philosophical Consequences", in The Primacy of Perception (Evanston: Northwestern University Press, 1964), 12-42, here 30. 


\section{Introduction}

The historical coincidence of Maurice Merleau-Ponty's phenomenology and the representational practices of Abstract Expressionist artists such as Barnett Newman and Jackson Pollock has often been noted, but the possible implications of the connection for interpretation have only occasionally been pursued in a sustained manner. ${ }^{3}$ The parallel development of the careers of these two figures is remarkable. Both Pollock (1912-1956) and Merleau-Ponty (1908-1961) attempted to resist and to negate the conventional conceptions governing our understanding of perception and representation. For Merleau-Ponty, this meant momentarily "break[ing] with our familiar acceptance" of our "natural attitude," one generated by powerful, but suspect, theoretical presuppositions about how we supposedly perceive the world. ${ }^{4}$ For Pollock, it meant suspending powerful cultural presuppositions about how paintings depict the world, and it meant investigating — via a radical technique — the form and content of representational practices. For both, it meant rejecting an "objective" viewpoint in order to comprehend the genesis of meaning in and through a subject's embodied perception. The goal of this paper is to explore how Merleau-Ponty's attempt to describe phenomenologically the "pre-objective," "pre-reflective" or "primordial" depth that funds reflective thought might illuminate Pollock's analogous effort to express that depth pictorially. ${ }^{5}$

3) Exceptions include Michael Fried, "Three American Painters," in Art and Objecthood (Chicago: University of Chicago Press, 1998), 213-68; Wayne J. Froman, "Action Painting and the WorldAs-Picture," in The Merleau-Ponty Aesthetics Reader, ed. G. A. Johnson (Evanston: Northwestern University Press, 1993), 337-47; Yve-Alain Bois, "Perceiving Newman," in Painting as Model (Cambridge: MIT Press, 1991), 186-211; Paul Crowther, "Barnett Newman and the Sublime," in The Language of Twentieth-Century Art: A Conceptual History (New Haven and London: Yale University Press, 1997), 149-63; and Galen A. Johnson, "The Invisible and the Unrepresentable: Barnett Newman's Abstract Expressionism and the Aesthetics of Merleau-Ponty," Analecta Husserliana 75 (2002): 179-89. See also Amelia Jones, "Meaning, Identity, Embodiment: The Uses of MerleauPonty's Phenomenology in Art History," in Art and Thought, ed. D. Arnold and M. Iversen (Oxford: Blackwell, 2003), 72-90.

4) Merleau-Ponty, of course, acknowledges that this suspension is never total: "The most important lesson which the reduction teaches us is the impossibility of a complete reduction" $(P P$, xiv).

5) Although the term "fund" might seem to call for a particular technical definition, I am using it to suggest the general idea of a resource upon which an individual draws - not necessarily consciously - for the purposes of establishing the immediate qualitative unity of the present. As I will discuss momentarily, Merleau-Ponty speaks of an "unreflective fund of experience" that reflective thought presupposes. It is possible to think of a fund as the sum total of interactions or experiences undergone or accumulated by the individual over time, experiences that might leave their 
My thesis is that Pollock's development of the drip, pour, and spatter technique in the years around 1947-50 generated certain unconventional representational possibilities, including the possibility of expressing the pre-reflective involvement of an embodied, intentional subject in a perceptual world. ${ }^{6}$ Pollock, I will suggest, thus discovered the means by which he could explore or investigate pictorially the pre-objective conditions of reflective and intellectual consciousness. Consequently, his painting-here I limit myself to an account of Number 1, 1949 (Figure 1) - motivates viewers to consider the relationship between intention and meaning as it appears in both primordial and reflective dimensions of experience. The account proceeds broadly in three stages. First, I review key features of Merleau-Ponty's concept of the preobjective and attempt to clarify the reflexive nature of investigating it by considering his analysis of Paul Cézanne's technique. Second, I consider Pollock's technique and some critical responses to it, while also analyzing some of its implications for a notion of pictorial address. Finally, I examine the perceptual effects of Number 1, 1949 and interpret them, following Merleau-Ponty's lead, in view of a revised understanding of the relationship between automatism and intention.

mark in conscious memory or in unconscious habits of thought, behavior, or feeling. My use of the term resonates with how it is employed by John Dewey, who referred throughout his writings to "funded" experience and meaning, but nevertheless avoided defining it precisely. For useful discussions, see Stephen C. Pepper, "The Concept of Fusion in Dewey's Aesthetic Theory," Journal of Aesthetics and Art Criticism 12, no. 2 (December 1953): 169-76, and Philip M. Zeltner, John Dewey's Aesthetic Philosophy (Amsterdam: B.R. Grüner, 1975), esp. 11-13.

6) A comment on these two terms-representation and expression-seems called for. I use "representation" in a general sense to refer to what an artist achieves when he or she gives form to experience (or thought, or feeling) through a medium (obviously, in this sense, representation has nothing to do with whether a painting is figurative or abstract). I want to distinguish my use of this term from representation understood as the classical mimetic paradigm in which thought and language are taken to represent an objective reality (a paradigm Merleau-Ponty struggled to defeat). As for "expression," my general sense of the term-and the meaning I hope my use of it carries-is informed by Lawrence Hass, who stresses that for Merleau-Ponty, expression was an operation "whereby some overwhelming initial form, figure, datum, or image, is creatively transformed and reorganized in a way that radiates new meaning or insight, and which brings a strong feeling of necessity" (Merleau-Ponty's Philosophy [Bloomington: Indiana University Press, 2008], $160)$. 


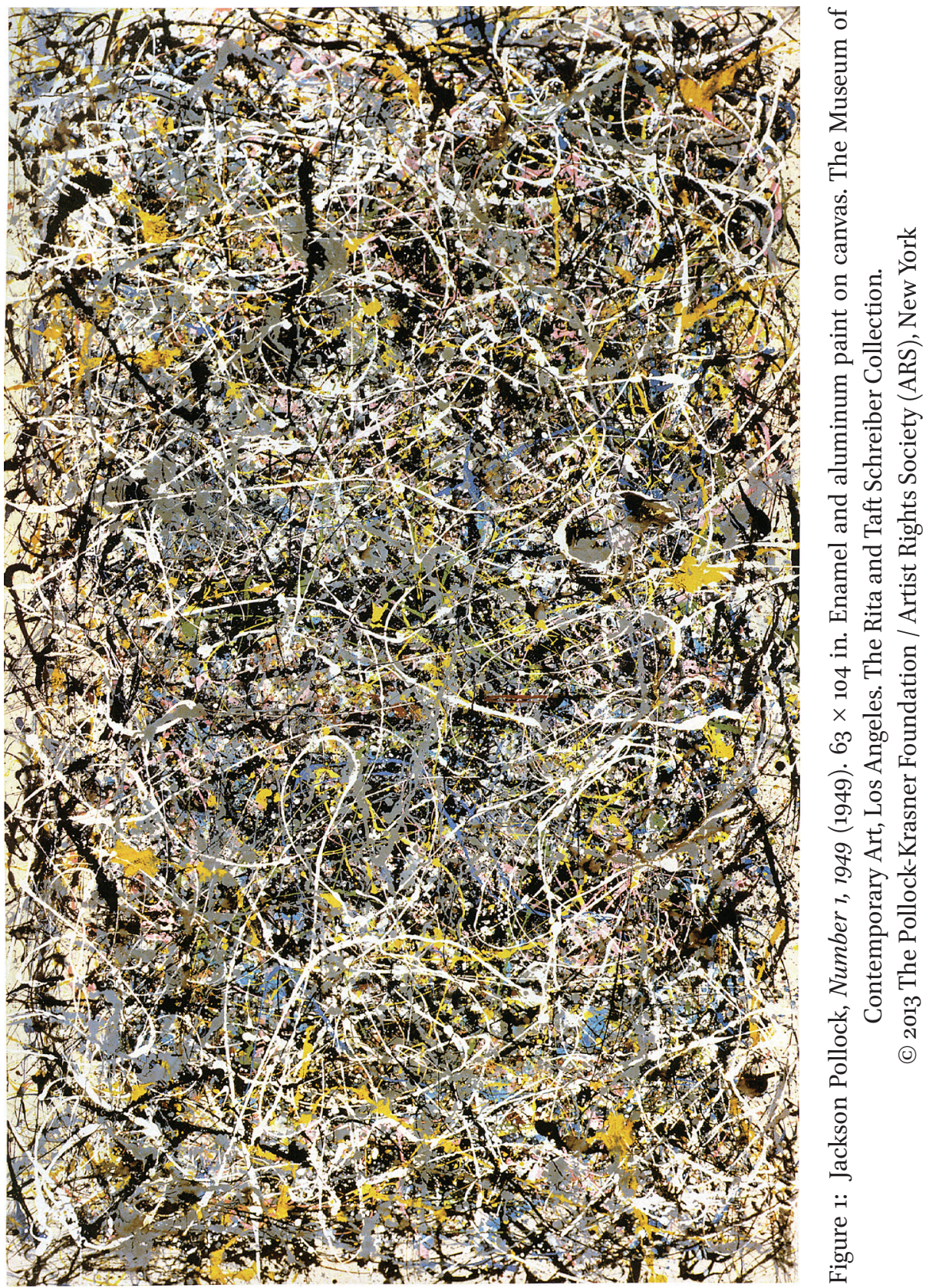




\section{The Pre-objective World}

Soon after Pollock's death in a car crash in 1956, a number of philosophers debated Merleau-Ponty's concept of a pre-objective world, a concept he had begun to fully develop in Phenomenology of Perception. ${ }^{7}$ Broadly speaking, Merleau-Ponty theorizes the pre-objective world to counter both empiricist and rationalist approaches to perception, which "reduce all phenomena which bear witness to the union of subject and world, putting in their place the clear idea of the object as in itself and of the subject as pure consciousness. [Objective thinking] therefore severs the links [that] unite the thing and the embodied subject" $(P P, 320)$. If science assumes and describes such an objective world, despite or even in the face of the modes of appearance that Merleau-Ponty is at pains to describe, then his concept of the pre-objective world can be understood as an attempt to critique the natural attitude and to establish a genetic phenomenology that explains the ways in which embodied perception operates in the world before it is measured, analyzed, or described by scientific discourse.

The pre-objective world is characterized by fundamental intentional bonds between subject and world that account for the immediate perceptual unity of that world and that fund-but are intertwined with - higher order reflexive, conceptual, or linguistic meanings. ${ }^{8}$ The pre-objective or primordial intentionality of consciousness is a general directedness towards the world that is the condition for meaning. Understood along these lines, the idea of pre-objective

\footnotetext{
7) See Michael Kullman and Charles Taylor, "The Pre-Objective World," in Essays in Phenomenology, ed. M. Natanson (The Hague: Martinus Nijhoff, 1966), 116-36; Thomas Munson, "The PreObjective Reconsidered," Review of Metaphysics 12 (1958/59): 624-32; and H. L. Dreyfus and S. J. Todes, "The Three Worlds of Merleau-Ponty," Philosophy and Phenomenological Research 22, no. 4 (June 1962): 559-65. My understanding of the place of the pre-objective in Merleau-Ponty's phenomenology in indebted to broad reading of the work of numerous scholars, among them: John Bannan, The Philosophy of Merleau-Ponty (New York: Harcourt, Brace \& World, 1967); John Sallis, Phenomenology and the Return to Beginnings (Pittsburgh: Duquesne University Press, 1973); Samuel B. Mallin, Merleau-Ponty's Philosophy (New Haven: Yale University Press, 1979); Gary Brent Madison, The Phenomenology of Merleau-Ponty (Athens: Ohio University Press, 1981); M. C. Dillon, Merleau-Ponty's Ontology (Evanston: Northwestern University Press, 1988); and M. M. Langer, Merleau-Ponty's Phenomenology of Perception: A Guide and Commentary (Tallahassee: Florida State University Press, 1989).

8) Merleau-Ponty does not accord temporal priority to this primary layer of existence. On this point, see J. C. Berendzen, "Coping Without Foundations," International Journal of Philosophical Studies 18, no. 5 (2010): 629-49.
} 
intentionality provides a counterweight to intellectualist positions that hold intentionality to be a matter of judgment or positing thought. Instead, it can be thought of as an "operative intentionality," in the sense of Edmund Husserl's "fungierende Intentionalität," a kind of primordial contact felt by a "lived body" of an original and material bond between the subject and the world. ${ }^{9}$ Because this intentionality is manifest as the lived body's concrete, spatial, and motile directedness to the world, meaning is an inherent possibility of our experience.

To clarify the intentional nature of the primordial bonds that bind the embodied subject to the world, Merleau-Ponty famously analyzes the experience of the phantom limb-in which he takes a patient's felt persistence of a missing appendage to be a certain refusal of its absence - to suggest that the lived body, properly understood, is not simply an object, but is rather a mode of inhabiting the world: "We must therefore avoid saying that our body is in space, or in time. It inhabits space and time. Consciousness is being-towardsthe thing through the intermediary of the body" $(P P, 138-39) \cdot{ }^{10}$ The embodied subject of primary perception is intentional (i.e., directed) but is not yet present to himself as a reflective or intellectual consciousness. Merleau-Ponty calls this subject "the anonymous one buried in the world" and asserts that it has a "global and inarticulate grasp upon the world."11 In taking a "pre-conscious possession of the world," the body-subject enters into a primordial reciprocity with the world in which subject and object mutually come into being $(P P, 298)$.

Genetic phenomenology illuminates the process by which a self-conscious, reflective subject emerges from the anonymity of the pre-conscious, preobjective world. "The task of a radical reflection," Merleau-Ponty wrote, "consists, paradoxically enough, in recovering the unreflective experience of the world":

What have we then at the outset? ... [A] certain perceptual field against the background of a world. Nothing here is thematized. Neither object nor subject is posited.... [P]rimary perception is a non-thetic, pre-objective and pre-conscious experience.... It is in the experience of the thing [within this primordial field] that the reflective ideal of positing thought has its basis. [R] eflection does not itself grasp its full significance unless it refers to the

\footnotetext{
9) On the relationship to Husserl, see Martina Reuter, "Merleau-Ponty's Notion of Pre-Reflective Intentionality," Synthese 118, no. 1 (January, 1999): 69-88.

10) Sentence order modified.

11) Merleau-Ponty, "Working Notes," in The Visible and the Invisible, ed. C. Lefort, trans. A. Lingis (Evanston: Northwestern University Press, 1968), 201; and in PP, 404, respectively.
} 
unreflective fund of experience which it presupposes, upon which it draws, and which constitutes for it a kind of original past, a past which has never been a present. $(P P, 241-42)^{12}$

Merleau-Ponty's phenomenology analyzes embodied perception in order to return intellectual consciousness to the roots of unreflective experience that funds and gives value to its higher order constructions. It recursively discovers an "original past," one that is not literal but that is posited by a reflective consciousness.

\section{The Originality of Pre-reflective Experience}

In the late 1930 s and early ' 40 s, while Merleau-Ponty was systematically dismantling the classical conception of physiological psychology in The Structure of Behavior (1942, trans. 1963) and preparing the ground for his analysis of embodied perception in Phenomenology of Perception (1945, trans. 1962), Pollock was working through a mode of physical realism that he hoped would visually stimulate kinesthetic sensations in the viewer through certain compositional strategies, conveying to them a sense of embodiment. Various scholars have ably reviewed the historical and aesthetic contexts of this effort, which found its origins in the teachings of Pollock's early mentor, Thomas Hart Benton, who had theorized about the literal transfer of muscular feeling through pictorial composition in the $1920 \mathrm{~s} .{ }^{13} \mathrm{But}$, as has often been argued, the content of Pollock's work between 1947-50 - during which time he abandoned his earlier modes of corporeal expression in favor of allover abstractionunderwent significant revision, if not radical change.

While generalizing about the characteristics of Pollock's allover surfaces tends to diminish efforts to put forward interpretations of particular paintings, it is also the case that a broad view of shared features helps establish the

\footnotetext{
12) Emphasis added. The last sentence reads in the original: "La réflexion ne saisit donc ellemême son sens plein que si elle mentionne le fonds irréfléchi qu'elle présuppose, dont elle profite, et qui constitue pour elle comme un passé originel, un passé qui n'a jamais été présent" (Merleau-Ponty, Phénoménologie de la Perception [Paris: Gallimard, 1945], 280).

13) Thomas Hart Benton, "The Mechanics of Form Organization, Parts I-V," The Arts (NovemberMarch, 1926). For a recent analysis, see Barbara Jaffee, "Jackson Pollock's Industrial Expressionism," Art Journal 63, no. 4 (Winter 2004): 68-79. Other sources for Pollock's commitment to physical realism included the Mexican muralists, most notably José Clemente Orozco and David Alfaro Siqueiros, Native American art, and, of course, the legacy of European modernism, particularly Pablo Picasso. For an overview of many of these connections, see Ellen Landau, Jackson Pollock (New York: Harry N. Abrams, 1989); and Stephen Polcari, Abstract Expressionism and the Modern Experience (Cambridge: Cambridge University Press, 1991).
} 
painter's intentions for some of their basic effects. The technique of dripping or pouring paint on a horizontally laid canvas from its fours sides was a means for Pollock to cover it with a multitude of marks, maximizing the number of interrelationships between them, and yielding, in Michael Fried's description, a "layered impactedness, mobile intensiveness, and experiential density of the painted surface."14 The simultaneous avoidance of definitively closed shapes or outlines produces an image resistant to stable figure-ground relationships, challenging - and perhaps ultimately inhibiting - the viewer's achievement of visual equilibrium (understood broadly as the reduction of tension between the viewer and the perceptual field, in this case, a visual, painted one). This thwarting of visual equilibrium has implications for how we interpret the modes of experience or consciousness Pollock's paintings express. Consider the point that Merleau-Ponty posits a body-subject who first experiences only a general directedness - an operative intentionality-towards the world through a primordial intentionality, but who subsequently comes to understand his or her subjectivity as generated in reciprocity with some stabilized field of figure-ground relations. Because the key perceptual effects of Pollock's work are closely related to this basic destabilization of figure-ground, considering the issue closely will ultimately help explain how his technique, and the pictorial fields it generates, can be interpreted as facilitating a viewer's recognition of the pre-objective conditions of reflective consciousness, and the primordial intentionality that subtends the emergence of the subject.

Although Merleau-Ponty never wrote about Pollock, he addressed figureground relations in "Cézanne's Doubt" (1945). In that essay, he presented the artist as a kind of phenomenologist, working against the assumptions of the natural attitude and carrying out his own form of critique of objectivism. Cézanne, Merleau-Ponty observed, distinguished between "the spontaneous organization of the things we perceive and the human organization of ideas and sciences." 15 His project responds to this division:

We see things; we agree about them; we are anchored in them; and it is with "nature" as our base that we construct our sciences. Cézanne wanted to paint this primordial world.... He wanted to put intelligence, ideas, science, perspective, and tradition back in touch with the world of nature ... "from which they came." (CD, 13-14)

\footnotetext{
14) Michael Fried, "Optical Allusions," Artforum 37 (April 1999): 97-101, 143, and 146; here 97.

15) Merleau-Ponty, "Cézanne's Doubt” [1945], J. Wild, ed., Sense and Non-Sense (Evanston: Northwestern University Press, 1964), 16; hereafter cited as CD followed by page number in the text.
} 
Looking at his paintings, a beholder experiences "the impression of an emerging order, of an object in the act of appearing, organizing itself before our eyes" $(C D, 14)$. This is a "lived perspective" that contrasts with a "geometric or photographic one" of the objectified world, and results in part from Cézanne's tendency to resist clear distinctions between figure and ground ("He did not want to separate the stable things which we see and the shifting way in which they appear" [CD, 13-14]). A key technical feature operates to complicate figureground relations, namely, the consistency of Cézanne's application of short, near-parallel brushstrokes over a range of depicted objects, from patches of landscape, to buildings, to foliage, even to the sky. The overall effect of Cézanne's touch is to collapse distinctions between background and foreground areas, since they share equal tactile, and thus visual, weight. Such physical regularity can be so insistent that it undermines the pictorial illusionism of the scene. ${ }^{16}$ The visual complexity generates an undecidable oscillation or pulse between figure and ground. The effect yields an impression of "matter as it takes on form, the birth of order through spontaneous organization" (CD, 13).

The significance of these pictorial effects for phenomenological inquiry becomes clearer when we consider them in light of Merleau-Ponty's attempt to establish the originality of pre-reflective experience. ${ }^{17}$ For Merleau-Ponty, a chief task of genetic phenomenology, as the name implies, is to investigate origins, "re-achieving a direct and primitive contact with the world, and endowing that contact with a philosophical status" $(P P$, vii). "[R]adical reflection," he continues, "amounts to a consciousness of its own dependence on an unreflective life which is its initial situation" ( $P P$, xiv). An immediate problem presents itself: since the nature of the origin must be discerned by thought, thought (however radical) confronts the difficulty of establishing the originality of something that escapes it. ${ }^{18}$ The non-discursive nature of painting, however, might enable an artist to express the primordial beginnings of reflective

16) Richard Shiff has done the most to elaborate the significance Cézanne's technique. For his discussion on Merleau-Ponty and Cézanne, see "Cézanne’s Physicality: The Politics of Touch," in The Language of Art History, ed. S. Kemal and I. Gaskell (Cambridge: Cambridge University Press, 1991), 129-180; esp. 150-54.

17) My points here are indebted to my reading of Sallis, Phenomenology and the Return to Beginnings.

18) Sallis asks: "How is the reflection, which takes as its task the illumination of what is intrinsically opaque to reflection, to understand itself, and what kind of thematization of that primordial stratum which it seeks to penetrate can appropriately be demanded of it?" (Phenomenology and the Return to Beginnings, 40). 
thought, the "ante-predicative life of consciousness" $(P P, \mathrm{xv})$, in a way that absorbs the paradox, accepting its recoil (as Merleau-Ponty's own writing aims to do).

But it is vital to acknowledge that the peculiar character of the artist's expression, like the phenomenologist's description, is reflexive. Cézanne's lived perspective is not actually experienced by a viewer in looking at the painting; that perspective is held in suspension, rendered pictorial. It is represented. The painter "freeze[s] these distortions [of the lived perspective] in repainting them on canvas; [he] stop[s] the spontaneous movement in which they pile up in perception" (CD, 14). This "freezing" is the condition for us to reflect on the meaning of the world of primordial perception, that "insurpassable plentitude" that for Merleau-Ponty is the "real" (CD, 15). If Cézanne's work "reveals the base of inhuman nature upon which man has installed himself," it does so because "only a human being is capable of such a vision which penetrates right to the root of things beneath the imposed order of humanity" (CD, 16). There is a fundamental reflexivity in Merleau-Ponty's project: the return to origins is not a literal one, for it is only from the point of view of the originated that the origin comes into focus. Cézanne's paintings recursively express pre-reflective experience, revealing the ground of our knowledge to be the "primordial historicity" of the lived body and the "there is' which underlies [scientific thinking]."19 Since that world exists only from a human perspective, we might understand Cézanne's expressive act — conveyed by his mode of pictorial address — as an attempt to discover the pre-objective conditions of reflective thought, its intentional self-grounding. Stated in another way, Cézanne expresses the relationship of pre-reflective to reflective experience in order to show us the conditions for creating meaning while creating it.

\section{II}

\section{The Interpretation of Origins and Depth}

In a slightly different sense of the term, investigating primordial "origins" as a platform for interpreting Abstract Expressionism has encouraged some scholars, drawing on phenomenology, to suggest that some artworks actually instantiate for a beholder an experience of the pre-reflective dimension of experience, in which objective categories of thought have not yet appeared and where

19) Merleau-Ponty, "Eye and Mind," in The Primacy of Perception, 160-161. 
subject and object appear merged. In his discussion of Barnett Newman, for instance, Yve-Alain Bois finds Onement I (1948) to "actualize ... something like an 'originary perception'," or "our birth-to-the-world." 20 Similarly, in a study of Mark Rothko, James Breslin suggests that the painter's works "travel back to give us subjectivity in the process of forming, prior to language, prior to the 'fall' into hard boundaries." ${ }^{21}$ The philosopher Galen Johnson suggests that Newman's works help the viewer overcome, through the apprehension of a beauty that "transcends the subject-object dichotomy," nothing less than the "philosophical dualism of subject and object [that] underlies the divisions in Western civilization between spirit and matter, self and world, mind and body."22 (Similarly, Merleau-Ponty found that Cézanne's work "returns to just that primordial experience from which these notions [the distinctions of soul and body, thought and vision] are derived and in which they are inseparable" $[C D, 16])$. Within this originary condition, the connection of the lived body to the world of primary perception is so close that the idea of two separate realms of experience, subjective and objective, threatens to become meaningless.

More recently, the art historian T. J. Clark has suggested that painting, in Pollock's hands, "might be able to put itself in a different relation to the world. To be 'in' it, or 'of' it, in ways which twist the familiar prepositions back on themselves." ${ }^{23}$ In discussing One: Number 31, 1950, Clark writes:

What was to be signified by the interlace now was the logic of a certain way of dealing with the world.... And yet this was clearly a kind of dealing that, given [the world's] existence at the edge of our normal categories, could only be pictured as "something like pure, disembodied energy." What shall we call it, this mode of experience? Vestigial? Immediate? Unfigured? Unfounded? (ibid., 334)

It is central to Clark's account that this mode of experience-whatever we call it - is "signified" (not lived or actually experienced). Instead, it is seen from the perspective of the "ruling symbolic regimes" of culture (ibid., 336). As a

20) Bois, "Perceiving Newman," 195.

21) James Breslin, “Out of the Body: Mark Rothko's Paintings," in The Body Imaged, ed. K. Adler and M. Pointon (Cambridge: Cambridge University Press, 1999), 43-52; 49.

22) Galen A. Johnson, The Retrieval of the Beautiful (Evanston: Northwestern University Press, 2010), 5. Johnson is not specifically talking about Pollock here, but his epigraph (a quote by Newman) suggests that the idea could apply to him.

23) T. J. Clark, Farewell to an Idea: Episodes from a History of Modernism (New Haven: Yale University Press, 1999), 333. Here, Clark quotes Fried, "Jackson Pollock," in Jackson Pollock: Interviews, Articles, and Reviews, ed. P. Karmel (New York: Museum of Modern Art, 1999), 98; hereafter cited as $J P I$. 
"wilderness," it is a space that is unoccupied by symbolic order; paradoxically, it is recognized as wilderness only through the symbolic. ${ }^{24}$ Like Clark, I think it would be wrong to consider Pollock's work as somehow giving us direct access to a content that is putatively beyond (or before) representation-that it is literally im-mediate. To make the mediated nature of the phenomenological description of pre-objective depth clear, Merleau-Ponty reminds us: "[W]e discover the unreflected. But the unreflected we go back to is not that which is prior to philosophy or prior to reflection. It is the unreflected which is understood and conquered by reflection." ${ }^{25}$ Pre-reflective experience, it deserves repeating, is "a past which has never been a present." It must be represented in order to be interpreted.

Still, there is a tendency, or a temptation, to speak of Pollock's paintings - as well as his technique of making them — as establishing so powerful a continuity between artist and his activity or between viewer and painting that the distinction between them collapses, leaving only an anti-representational immediacy called, in the gestalt psychologist Anton Ehrenzweig's memorable phrase, "undifferentiated oceanic envelopment." ${ }^{26}$ Pollock perhaps sanctioned such views in his account of being "in" his paintings, of having "contact" with them, and of feeling as if he were a "part" of them. ${ }^{27}$ Early critics followed the artist's lead in emphasizing this bond. In 1950, Bruno Alfieri wrote that "Pollock has broken all barriers between his picture and himself: his picture is the most immediate and spontaneous painting. Each one ... is part of himself." 28 In his 1959 monograph, the poet Frank O'Hara extended this measure of indivisibility to the viewer's experience of Pollock's imagery. A viewer apprehends a "oneness which has no need for the mediation of metaphor or symbol." 29 Anna Chave finds " $[\mathrm{t}$ ] he effect of Pollock's classic poured and drip paintings [to be] cosmic or oceanic, like the infinity of the universe." 30 These evaluations

24) Clark writes: "There is a kind of experience, these pictures say, that is vestigial, by the looks of it - unusable, marginal, uncanny in the limiting sense of the word-but that at least the parent culture leaves alone" (Farewell to an Idea, 335-36).

25) Merleau-Ponty, "The Primacy of Perception and Its Philosophical Consequences," 19.

26) Anton Ehrenzweig, The Hidden Order of Art (Berkeley: University of California Press, 1971), 120. Hereafter $H O A$, followed by page number.

27) Pollock, “My Painting," JPI, 17-18.

28) Bruno Alfieri, "A Short Statement on the Painting of Jackson Pollock," JPI, 69.

29) Frank O'Hara, Jackson Pollock (New York: George Braziller, 1959), 29.

30) Anna C. Chave, "Pollock and Krasner: Script and Postscript," [1993], in Jackson Pollock: New Approaches, ed. K. Varnedoe and P. Karmel (New York: Museum of Modern Art, 1999), 262-79; 271 and 275 . 
suggest a sense of continuity or even merger between painter/viewer and painting that circumvents the need for interpretation. For his part, Ehrenzweig firmly stressed the feeling that Pollock's works literally "sucked and enveloped the spectator inside the picture plane," producing a "manic experience of mystic oneness." 31 And although ultimately recuperated by a secondary process that confers structure on the indeterminate phenomena, the experience is anti-representational enough while it lasts. When one looks at Pollock,

[t]he surface gestalt lies in ruins, splintered and unfocusable, the undifferentiated matrix of all art lies exposed, and forces the spectator to remain in the oceanic state of the empty stare when all differentiation is suspended. The pictorial space advances and engulfs him in a multi-dimensional unity where inside and outside merge. (HOA, 121)

While the elimination of subject-object distinctions in these accounts might seem to converge on Merleau-Ponty's sense of pre-reflective experience, they nonetheless imply the suspension of the reflective thinking that MerleauPonty theorizes is necessary to rediscover, to "conquer," the pre-objective. And, it runs counter to my claim that in Pollock's work, the pre-reflective is represented - that it is expressed pictorially.

\section{Pictorial Address}

It is significant that Pollock's own testimony regarding his procedure implies an awareness of just this issue. He recognizes a distinction between the enactment of something like primordial perception (on the part of the painter as he paints) and the pictorial mediation necessary to express the pre-reflective so that it can come into view. The artist explained:

\footnotetext{
On the floor, I am more at ease. I feel nearer, more a part of the painting, since this way I can walk around it, work from the four sides and literally be in the painting. ... [But] [w]hen I am in my painting, I'm not aware of what I'm doing. It is only after a sort of "get acquainted" period that I see what I have been about. ... It is only when I lose contact with the painting that the result is a mess. Otherwise there is pure harmony, an easy give and take. ${ }^{32}$
}

Here, Pollock speaks, first, of a kind of immersion: being "in" the painting both literally and metaphorically, even to the point that he is so absorbed in his activity that he is "not aware of what [he's] doing." Second, he suggests an

\footnotetext{
31) Ehrenzweig, $H O A, 118-19$.

32) Pollock, "My Painting," JPI, 17-18.
} 
identification: being "a part of the painting," in such radical "contact" with it that a loss of contact results in failure. Pollock enacts such a proximate connection between himself (subject) and his painting (object) that the distinctions between the two are all but obviated. Yet in opposition to this sense of merger, Pollock also refers to experiencing a feeling of reciprocity: "an easy give and take." Unlike identification or merger, reciprocity necessarily implies a transaction between two entities that must be considered somewhat distinct from one another, even if their mutual exchange constitutes them as entities. Pollock evidently experiences this reciprocity as a balance between painter and painting. Finally, there is his description of a "'get acquainted' period" during which he steps back, as if to separate himself completely from his work, in order to "see what [he's] been about;" we might say, to reflect. ${ }^{33}$

Recently, Michael Fried has written about this oscillation between merger and separation — between identification and reciprocity—in terms that I think greatly illuminate Pollock's practice. Fried (in a discussion of Caravaggio) identifies a "moment,"

of extended duration, of the painter's engagement in the ongoing, repetitive, partly automatistic act of painting; I call that "moment" immersive, imagining the painter as so caught up, so immersed, in this phase of his work on the painting ... as to be less than fully aware of any sharp distinction between the painting and himself[; $]^{34}$

and he distinguishes it from a second "moment,"

notionally instantaneous, of separating or indeed recoiling from the painting, of becoming detached from it, which is to say of no longer being immersed in work on it but rather seeing it, taking it in, as if for the first time; I call that "moment" specular. (MC, 39)

The contrast between the two "moments" (not to be understood as strictly chronological) indicates the artist's achievement in establishing the image as a

33) As Harry Cooper pointed out to me, it is also possible that the " 'get-acquainted' period" Pollock refers to occurs as the artist is immersed in the activity of painting and would thus be a key phase in the dialogic process by which Pollock comes to know what he was trying to accomplish.

34) Fried, The Moment of Caravaggio (Princeton and Oxford: Princeton University Press, 2010), 39; hereafter cited as $M C$, followed by page number. The themes of merger and separation (or specularity) run throughout Fried's works; see especially Courbet's Realism (Chicago: University of Chicago Press, 1990). On specularity and merger in the work of Henri Matisse, see Todd Cronan, Against Affective Formalism: Matisse, Bergson, Modernism (Minneapolis: University of Minnesota Press, 2013). 
painting addressed to a beholder reciprocally, in what Fried calls "a relationship of mutual facing” (MC, 39). Pollock's representation of-and reflection on-the pre-reflective occurs pictorially, as a matter of an intentional mode of pictorial address. The notion demands a distinction between an object (artwork) that addresses and a subject (beholder) who is addressed.

\section{III}

\section{Attention, Frame, and Format}

Aspects of Fried's immersive moment resonate with what I have been describing as Pollock's investigation of the pre-reflective. Above, I quoted MerleauPonty describing the lack of distinctions in primary perception, where "neither object nor subject is posited" and where a "pre-conscious," automatistic mode of experience obtains. Yet how is a transition to reflection achieved? How does the primary perception of an embodied subject transform or develop into thought and expression? The reader will have anticipated that I see Number 1 , 1949 as helping to answer these questions. But the answers must be given in terms of an interpretation of pictorial and perceptual effects, using MerleauPonty as a guide. So, in arguing that Number 1, 1949 presents viewers with the opportunity to reflect on the pre-objective world, I do not want to imply that the painting actually depicts what that world might look like, as if it were a view onto some primordial scene. Nor do I want to suggest that it somehow permits a beholder literally to experience such a world, as if the act of viewing generates an unmediated affective response to a primordial environment.

The painting is about five feet high and eight and a half feet long, and consists of about seven colors in enamel (mostly white, black, yellow, and aluminum but also blue and pink). Pollock applied the white enamel last or nearly last, and its filament-like loops and arcs appear as a kind of tracery responding to the splotchy spatters of aluminum, yellow, and blue below. Underneath it all, but interwoven with everything else, is a staccato web of black pours, spatters, and throws of varying thickness, density, and sheen. It is difficult for a viewer to select from the surface any single pictorial incident that seems to impinge upon attention more than any other. Additionally, there initially appears neither an internal nor external frame of reference according to which a viewer might organize the field hierarchically. Like the uniformly dispersed pictorial incidents, our eyes' focus and our mental attention is allover, finding no place to rest and centered nowhere in particular (although it is also true 
that the eye is in some measure guided by the delicate, yet assertive, thrown white tracery). When the eyes, eventually tiring of rapid scanning, become less intent either on following visual paths or on the difficult task of focusing on particulars, the surface appears somewhat degraded, a homogenous millingabout of flecks and specks. Asked by William Wright in $195^{\circ}$ how an individual should look at his work, Pollock replied, "I think they should not look for, but look passively." ${ }^{35}$ In doing so, we would not yet have begun to discriminate one "thing" from another (or indeed, to differentiate our "selves" from our environment): in short, our selective activity, our attention, would not yet have begun to play a decisive role in bringing structure to our experience. ${ }^{36}$

Merleau-Ponty's characterization of the pre-objective world, and the mode of primary perception taking place within it, illuminates aspects of these pictorial effects. In pre-reflective experience, the organism is unable to organize objects into a unified perspectival field against which environmental changes (such as a modification to the angle from which we view the object due to our movement) could be stabilized. As Merleau-Ponty writes, "the sensory field [does not remain] stable while the subject perceives.... [There is] no univocal position, because no spatial framework persists from one perception to another" $(P P, 29)$. Additionally, figure-ground distinctions remain persistently uncertain or undecided. To explain how we move from this indeterminate horizon to the structured world we perceive in lived experience (which is not to suggest that our world is not without ambiguity), Merleau-Ponty analyzes the concept of attention, which "transform[s]" the primary perceptual field and allows consciousness "to be present to its objects":

The first operation of attention is, then, to create for itself a field, either perceptual or mental, which can be 'surveyed' (überschauen), [so that] consciousness does not

\footnotetext{
35) Pollock, "Interview with William Wright," JPI, 20.

36) My description of the homogeneity of the surface and its resultant de-differentiation of secure figure-ground relationships should not be taken as implying that Pollock actually defeats figureground perception. To do so is an impossibility. In criticizing the concept of an isolatable datum of perception, Merleau-Ponty writes: "A figure on a background is ... the very definition of the phenomenon of perception, [it is] that without which a phenomenon cannot be said to be perception at all. The perceptual 'something' is always in the middle [milieu] of something else, it always forms part of a 'field.' A really homogenous area offering nothing to be [perceived] cannot be given to any perception" $(P P, 4)$. Experimental findings of Gestalt psychology confirm that even when a subject is placed in a situation where there is a lack of external stimulation (such as in front of a blank wall in low level lighting), she will still perceive figures against uniform grounds, figures that are often generated by internal somatic events (e.g. heartbeats or breathing). See M. C. Dillon, Merleau-Ponty's Ontology, 6o-61.
} 
correspondingly lose what it has gained and, moreover, [does not] lose itself in the changes it brings about. $(P P, 29)$

If the primary level of experience is characterized by immersion in a perceptual field, then attention is the operation that allows a subject to detach herself from that field and to assume a specular position in relation to it. Attention, moreover, is actively creative, not passively acquisitive. It does not just permit our acquiring information about a world that is already constituted before our attending to it. Rather, attention achieves a world by responding appropriately, but spontaneously, to its solicitations:

[With regard to] the object of attention itself [,] [the act of attention] is literally a question of creation.... To pay attention is not merely further to elucidate pre-existing data, it is to bring about a new articulation of [data]... [Attention is] the active constitution of a new object which makes explicit and articulate what was until then presented as no more than an indeterminate horizon. $(P P, 29-30)$

Attention creates. The solicitation of our attention is not, or not merely, caused by objects but occurs spontaneously, generated by the drive of the organism to achieve equilibrium. ${ }^{37}$ Counter to empiricist and intellectualist positions, according to which attention merely clarifies what is already given, MerleauPonty suggests that attention inaugurates that primordial reciprocity by which we come into existence as subjects $(P P, 53)$.

The process can be interpreted in view of Number 1, 1949. When the beholder attends to center of the painting, another effect gradually modifies the homogenous, de-differentiated perceptual field I described above. It is not exactly that the center of the painting becomes a zone of clarity, but that an elliptical area around the center of the painting, about four feet across, appears as an area of relative stability, set off against a fringe of amorphous or unstructured activity that appears to surround it. Much of this has to do with the way Pollock leaves the corner zones relatively sparse of pictorial incident, yet fastens the web to those corners with loops whose tightness contrasts with the comparative looseness of linear tracery in the middle zone. The recession of the web from the corners of the frame and the consequent kneading-in of space at those zones makes them salient for the whole. The faint structure given by this

37) For William James, attention is a "reactive spontaneity," and thus "experience is what [we] agree to attend to" (see Principles of Psychology, 2 vols. [New York: Dover, 1950], 1:402). He continues: "[E] ach of us literally chooses, by his ways of attending to things, what sort of universe he shall appear to himself to inhabit" (1:424). 
perceived ellipse slightly counters the allover quality of the surface. ${ }^{38}$ In 1956 , Sam Hunter noticed a quality of Pollock's works that seems to hold especially in this case: "It is as if Pollock's fine lyricism must repeatedly be wrested free from the anonymous seething of brute, pigment matter. Yet, powered by an intense dynamism ..., structure break[s] through and rise[s] out of the primal disorder ... at the origin of Pollock's world." ${ }^{39}$

Perhaps another way to put it is to say that the effect of visual degradation in Number 1,1949 is achieved as if in opposition both to a sense of the perceived limits of the image (where it appears to end) and to a sense of the picture's physical edges, its frame (where it literally ends). Simply put, the surface's dedifferentiation, its uniformity and lack of hierarchy, compromises the power of its external boundaries, perceived or literal, to establish pictorial structure. At the same time, though, the internal framing of the ovoid provides a certain emergent structure to the image that restores to the painting a degree of pictorial cohesiveness that is more or less independent of both its perceived limits and the literal frame, as if the pictorial structure is now understood to be generated from the inside out, from the interior of the image to its frame, rather than the other way around. ${ }^{40}$

The relationship between the viewer's perception of this structure and the specific manner in which the painting solicits this perception is reciprocal in the sense that it is not merely given (as if the painting were a stimulus causing an automatic response) but is achieved through an act of attention.

38) William Rubin (following Clement Greenberg) made an important formal connection between the kind of fading away from the frame I am describing and the way the scaffolding of the 1911-12 works of Picasso and Braque tended to fade away from three edges of their paintings (usually excepting the bottom edge). But perhaps more importantly, Rubin indicated their connection to Piet Mondrian's seascapes and facades of 1913-14 (notably his "Pier and Ocean" series), where the "dissolution of the scaffolding near the edge is consistently carried out on all four sides" ("Jackson Pollock and the Modern Tradition: Part III," Artforum 5 [April 1967], 18-31; here 21). The artist Tony Smith testified on two occasions to Pollock's own affirmation of the precise connection to Mondrian (see Rubin, 23; and E.A. Carmean, Jr. "Jackson Pollock: Classic Paintings of 1950," American Art at Mid-Century [Washington, D.C.: National Gallery of Art, 1978], 127-53; 150 and 153n73, and Landau, Jackson Pollock, 196 and 262n28). On these and related points, see Michael Schreyach, "Pollock's Formalist Spaces," Nonsite 2, no. 7 (October 11, 2012) (http://nonsite.org/ article/pollocks-formalist-spaces).

39) Sam Hunter, "Jackson Pollock: The Maze and the Minotaur," in New World Writing: Ninth Mentor Selection (New York: New American Library, 1956), 174-92; 190-91.

40) For a discussion of related issues in the work of Cézanne and Picasso, see Charles Palermo, "A Project for Wholeness," in Eik Kahng et al., Picasso and Braque: The Cubist Experiment, 1910-1912 (Santa Barbara, CA: Santa Barbara Museum of Art, 2011), 15-37. 
Solicitation and response are bound in a productive interplay that does not isolate the person who senses (the sensor) from that which is sensed (the sensible). In Merleau-Ponty's words,

The sensor and the sensible do not stand in relation to each other as two mutually external terms.... [In] [the] transaction between the subject of sensation and the sensible it cannot be held that one acts while the other suffers the action, or that one confers significance on the other.... [A] sensible datum which is on the point of being felt sets a kind of muddled problem for my body to solve. I must find the attitude which will provide it with the means of becoming determinate.... I must find the reply to a question which is obscurely expressed. And yet I do so only when I am invited by it. $(P P, 214)^{41}$

The initial de-differentiation of Number 1, 1949 is the muddled problem that the perception of this ellipse solves. In addition — and to switch gears somewhatI want further to suggest that this solution (if that is the right word) might cause the viewer to become aware of, or to draw, a crucial distinction between two competing notions of pictorial structure. The first depends upon the degree to which the composition of elements within an array is seen to be adjusted to an external limit, specifically to the literal frame (I will call this notion "framed"). The second depends on a qualitative difference between how the total array, the allover visual field-which is something more than just the accumulation of separate marks - relates to that literal frame (I will use the term "format" to signify the qualitative difference). If she attends to the framed structure, the viewer might see the painting in one of two ways. Either she projects a narrative of Pollock's physical interaction with his surfacesand perhaps senses his "easy give and take" with his paintings-by taking his marks to represent the coordination and reciprocity involved in creating them. ${ }^{42}$ Or, alternatively, she might take the relations between those elements and each other (and to the frame) to index mere automatic reactions, with the result that Pollock's field threatens to be understood as the product of mechanical cause and effect, of sheer stimulus and reflex response-not as an instance of the spontaneous, creative expression of depth.

To understand those marks either as visualizing reciprocity or else as indexing cause and effect opposes the interpretation I would like to propose. I have been insisting that Pollock expressed something about how pre-reflective,

\footnotetext{
41) Merleau-Ponty was speaking specifically about the problem of color here, but I think it can be extended to the property of structure as well. Cf. Sallis, Phenomenology and the Return to Beginnings, $76-77$.

42) Pollock, "My Painting," JPI, 18.
} 
embodied intentionality might come to be coordinated reciprocally with an emergent setting, a world (here, the physical limits of the canvas surface), and it is here that the notion of format comes into play. In attending to format, viewers might also recognize that the particular marks, lines, pools, smudges, colors, and viscosities that may appear either as automatic signs or as indications of coordination are also subsumed by the web as part of the painting's allover visual field. And this field has a different relation to the frame than do the marks that constitute it. Above, I suggested that the de-differentiation of Number 1, 1949 was countered by an elliptical structure apprehended when the gaze of a viewer focuses on the center of the field, a structure that creates the sense of the painting as a whole. I would now like to suggest that the constitution of that totality is format. It is as if format, as a representational possibilitythat is, as a structure that functions as a medium to convey expressive content, versus a merely literal shape-is to be understood itself as emergent from the figurative depth of the field, not given beforehand. ${ }^{43}$ On this account, format is the medium through which the expression of pre-reflective, embodied intentionality is achieved and through which reflective consciousness might "grasp its full significance" as intertwined with and emergent from a pre-objective setting $(P P, 242)$.

\section{Automatism and Embodied Intentionality}

Pollock's technical facility - think of it as an exceptional coordination of bodily kinesthetics (comprised of both conscious actions as well as unconscious automatisms) with the physical properties of his materials, along with a recognition of the representational possibilities such a coordination createsenabled him to produce complex compositions within a framed area. Yet he produced something more than just a virtuoso example of composing multiple and seemingly infinitely varied elements positioned in relation to one another and to the literal frame of his canvases (no matter how interesting a viewer might find such compositions to be). Pollock also achieved format in the special sense in which I have been using the term: he reveals to a beholder a visual field that, far from being an accumulation of marks that are taken as traces or indexes of his movements or actions above the canvas, is expressive of the

\footnotetext{
43) Aspects of my analysis follow Fried's lead in "Shape as Form: Frank Stella's Irregular Polygons," reprinted in Art and Objecthood: Essays and Reviews (Chicago: University of Chicago Press, 1998), 77-99.
} 
creative intentionality of the body's conscious actions and its automatisms. The two levels are interfused. ${ }^{44}$

Automatism here appears in an unusual way. Pollock's automatism, like that associated with the Abstract Expressionists generally, is usually understood as an appropriation of surrealist automatism, itself understood as a technique for generating unconventional imagery. The term covers a set of deliberately employed techniques or procedures and is taken to be the means by which an artist circumvents her usual sense of intentional activity in order to access a level of experience 'beyond' or 'below' it. ${ }^{45}$ It is not my motivation here to review the complexities of that historical appropriation. Rather, I want to suggest that thinking of automatism as merely a technique-either one that is consciously utilized to circumvent skill and control in the creation of novel imagery, or that actually induces in the artist a mental or physical state that suppresses reflection or conscious control-has adverse consequences for understanding Number 1, 1949. Automatism, if it is to be interpreted-if it is to mean anything at all-must be taken, however paradoxical it initially sounds, as represented in Pollock's work, and as expressed by it. In Number 1, 1949, automatism is expressed as the basic intentionality of our situation in the world, analogous to pre-objective depth. ${ }^{46}$

Considered as a mode of mental or bodily comportment, of general directedness, this modified understanding of automatism might share something

44) In his discussion of Courbet's The Quarry (1856-57), Fried argues that in all acts and states "will and automatism are interfused"; Courbet calls into question the "absoluteness of the distinction between automatism and volition" (Courbet's Realism, 280). I follow Fried on this point, although I substitute Merleau-Ponty's “intentionality” for Fried's “volition.”

45) In contrast to this narrow view, Charles Palermo offers a compelling account of automatism in Fixed Ecstasy: Joan Miró in the 1920s (University Park: Pennsylvania State University Press, 2008), esp. 82-96. For historical perspectives see William Seitz, Abstract Expressionist Painting in America (Cambridge, MA: Harvard University Press, 1983) and Irving Sandler, The Triumph of American Painting (New York: Harper \& Row, 1970).

46) My analysis here is not the same as, but shares features with, Stanley Cavell's. Cavell speaks of discovering an artistic medium — which is not the same thing as its material basis - as discovering an "automatism." An artist who "investigat[es] what it is at any time that has provided a given work of art with the power of its art as such" is capable of creating a medium, an automatism -in short, of making compelling art. In addition, Cavell suggests that the point of this investigation is "to free [the artist] not merely from [his] confinement in automatisms that [he] can no longer acknowledge as [his own] [i.e., those given by tradition] . . but to free the object from [the artist], to give new ground for its autonomy." He succinctly put the point with regard to Pollock: "The surrealists looked for automatisms which would create images; Pollock looked for an automatism with which to create paintings" (Stanley Cavell, The World Viewed (Cambridge: Harvard University Press, 1979), 107-8. 
with pre-reflective experience, with what Merleau-Ponty called a "generalized 'I think' " in which the self is "a field, an experience." 47 The expression of this mode of awareness is what allows its opacity to be acknowledged (but not fully transcended) by reflective consciousness. ${ }^{48}$ Merleau-Ponty makes it clear that this opacity does not exist before it is expressed:

The relation of . . reflection to the unreflective ... is [a] two-way relationship ... [T] he founding term, or originator ... is primary in the sense that the originated is presented as a determinate or explicit form of the originator, which prevents the [originator] from reabsorbing the [originated], and yet the originator is not primary in the empiricist sense and the originated is not simply derived from it, since it is through the originated that the originator is made manifest. $(P P, 394)$

Although it confounds easy explication (and ill fits conventional modes of academic argumentation), what Merleau-Ponty attempted to describe and what Pollock, in view of the argument I have made, attempted to express pictorially, is a movement from something latent to something manifest while neither eliminating the original opacity of the latent nor forgetting the rootedness of the manifestly expressed in it. For Merleau-Ponty, there simply is no foundational world "before" the one we inhabit. His conception of the pre-objective recognizes the spontaneity of meaning. The individual establishes meaning by attending to the world, by paying attention, and in so doing constitutes "new objects" that make explicit what was before inarticulate. Perhaps this is part of the meaning of Number 1, 1949. Pollock's painting is an originated that enables the expression of an originator. It thus opens to a beholder the possibility for reflecting on the condition by which a subject emerges from a world, for reflecting on primordial depth, a past which has never been a present. ${ }^{49}$

\footnotetext{
47) PP, 403 and 406. Quoted by Sallis, Phenomenology and the Return to Beginnings, 66.

48) Sallis points out, however, that Merleau-Ponty's conceptualization of a tacit cogito that is to be transcended implies a certain immanence or interiority 'behind' experience that undermines his attempt to move beyond the idea of a constituting consciousness and consciousness-object relations. To invoke transcendence, that is, suggests a "recess of pure consciousness which is aloof from the world and out of which the transcending movement proceeds" (Phenomenology and the Return to Beginnings, 70).

49) The author thanks Claude Cernuschi, Galen Johnson, Pepe Karmel, Michael Kelly, and especially Todd Cronan and Charles Palermo for their comments on earlier drafts of this essay.
} 